\title{
A CONSTRUC̣ÃO DE UM PROCESSO DIDÁTICO-PEDAGÓGICO DIALÓGICO: ASPECTOS EPISTEMOLÓGICOS ${ }^{1}$
}

\begin{abstract}
RESUMO: No presente trabalho procura-se caracterizar conhecimentos e práticas do grupo de investigadores no ensino de Ciências que originou e implementou os Três Momentos Pedagógicos (3MP), denominados Problematização Inicial, Organização do Conhecimento e Aplicação do Conbecimento. A análise realizada com base em critérios epistemológicos de Ludwik Fleck teve como referência aspectos teóricos e dados de práticas, contidos em dissertações, teses, livros e artigos produzidos por membros desse grupo de investigadores. Dentre os resultados, destaca-se que o contexto da proposição dos 3MP é decorrência da transposição da concepção de Paulo Freire para a educação escolar e teve como referência três grandes projetos: um desenvolvido na África e dois no Brasil.
\end{abstract}

Palavras-chave: Três Momentos Pedagógicos; Freire; Fleck.

\section{THE CONSTRUCTION OF A DIALOGIC TEACHING-LEARNING PROCESS: EPISTEMOLOGICAL ASPECTS}

ABSTRACT: In the present work, we aim to characterize the knowledge and practices of the group of researchers in Science/Physics education who originated and implemented the Three Pedagogical Moments (3PM), called Initial Problematization, Knowledge Organization and Application of the Knowledge. The analysis, based onLudwik Fleck's epistemological criteria, had as reference theoretical aspects and practice data available in dissertations, theses, books and articles produced by members of this research group. The resultspoint out that the background of the proposition of 3PM is a result of the transposition of Paulo Freire's concept of school education, and had as reference three major projects: one developed in Africa and two in Brazil.

Keywords: Three Pedagogical Moments, Freire, Fleck.

\author{
Cristiane Muenchen* \\ Demétrio Delizoicov **
}

*Doutora em Educação
Científica e Tecnológica pela
Universidade Federal de Santa
Catarina (UFSC). Professora
Adjunta do Departamento
de Física e do Programa de
Pós-Graduação em Educação
em Ciências: Química da Vida e
Saúde da Universidade Federal
de Santa Maria (UFSM).
E-mail: crismuenchen@yahoo.
com.br
* *Doutor em Educação/
Didática pela Universidade de
São Paulo (USP). Professor
Assistente 2 do Programa de
Pós-Graduação em Educação
Científica e Tecnológica da
Universidade Federal de Santa
Catarina (UFSC).
E-mail: demetrio@ced.ufsc.br




\section{INTRODUÇÃO}

De acordo com Pierson (1997), no processo de apropriação e incorporação dos elementos freirianos nos projetos de ensino de Ciências/Física ${ }^{2}$, os Três Momentos Pedagógicos (3MP) - Problematização Inicial, Organização do Conhecimento e Aplicação do Conhecimento - são, juntamente com os conceitos unificadores (ANGOTTI, 1991), elementos desenvolvidos que passam a ter presença marcante tanto nas propostas de intervenção quanto nas investigações e publicações de seus pesquisadores.

Essa dinâmica didático-pedagógica, conhecida como os "Três Momentos Pedagógicos", fundamentada pela perspectiva de uma abordagem temática (DELIZOICOV, ANGOTTI e PERNAMBUCO, 2002) e abordada inicialmente por Delizoicov (1982), ao promover a transposição da concepção de educação de Paulo Freire para o espaço da educação formal, pode ser assim caracterizada:

Problematização Inicial: apresentam-se questões ou situações reais que os alunos conhecem e presenciam e que estão envolvidas nos temas. Nesse momento pedagógico, os alunos são desafiados a expor o que pensam sobre as situações, a fim de que o professor possa ir conhecendo o que eles pensam. Para os autores, a finalidade desse momento é propiciar um distanciamento crítico do aluno ao se defrontar com as interpretações das situações propostas para discussão e fazer com que ele sinta a necessidade da aquisição de outros conhecimentos que ainda não detém. Organização do Conhecimento: momento em que, sob a orientação do professor, os conhecimentos necessários para a compreensão dos temas e da problematização inicial são estudados; Aplicação do Conhecimento: momento que se destina a abordar sistematicamente o conhecimento incorporado pelo aluno, para analisar e interpretar tanto as situações iniciais que determinaram seu estudo quanto outras que, embora não estejam diretamente ligadas ao momento inicial, possam ser compreendidas pelo mesmo conhecimento.

Para Pierson (1997), em uma "primeira aproximação", podemos olhar os momentos pedagógicos como três momentos que:

devem se suceder no processo de ensino e aprendizagem: o primeiro momento de mergulho no real, o segundo caracterizado pela tentativa de apreender o conhecimento, já construído e sistematizado, relacionado a este real que se observa e o terceiro momento de volta ao real, agora de posse dos novos conhecimentos que permitam um novo patamar de olhar (PIERSON, 1997: 156).

Assim, na perspectiva de melhor entender a gênese e implementação dessas práticas educativas procura-se, com base em uma abordagem epistemológica, compreender as origens, os pressupostos teóricos e as diferentes formas de utilização dessa dinâmica. Ou seja, é possível considerar os 3MP como práticas pedagógicas, teoricamente fundamentadas, compartilhadas por esse grupo caracterizado por Pierson (1997) e cuja trajetória da produção é objeto de análise neste artigo. 


\section{ENCAMINHAMENTO TEÓRICO-METODOLÓGICO DA PESQUISA}

Nesta pesquisa procura-se caracterizar os processos da produção de conhecimentos que culminaram com a proposição dos 3MP pelo grupo de investigadores em ensino de Ciências/Física. Assim, uma análise com base em critérios epistemológicos se apresenta como um dos fundamentos para a compreensão desses processos. No entanto, como são processos datados e que, portanto, têm a sua historicidade, a definição dos critérios básicos para esta análise são mais, propriamente, os de caráter histórico-epistemológicos.

A produção e proposição dos 3MP pelo grupo de investigadores foram possíveis tanto pelas contribuições individuais, na medida em que cada um aprofunda determinados aspectos nas respectivas dissertações e teses, de acordo com Pernambuco (1994), quanto pelas articulações entre elas, que se construíram a partir da atuação conjunta de constituintes do grupo em projetos educacionais cujas premissas básicas eram comuns e compartilhadas entre todos. Assim, as interações estabelecidas entre si pelo grupo, ao implementarem práticas educacionais e submetê-las às análises críticas nas respectivas dissertações e teses, parecem ter um papel na produção dos 3MP que precisa ser resgatado e analisado. Nesse caso, os critérios histórico-epistemológicos de referência a serem adotados precisam também contemplar essa dimensão interacionista que caracteriza a produção do grupo.

Dessa forma, uma análise com base em critérios histórico-epistemológicos de Ludwik Fleck, principalmente com relação à categoria circulação intracoletiva e intercoletiva de ideias, se apresentou como um dos fundamentos para a compreensão desses processos.

Ludwik Fleck desenvolveu sua reflexão epistemológica influenciado pela Escola Polonesa de Filosofia da Medicina. O livro La Génesis y el Desarrollo de un Hecho Científico (FLECK, 1986) foi escrito com o intuito de contrapor-se à concepção de ciência do Círculo de Viena. O autor fez críticas ao empirismo lógico e sua produção é contemporânea à de Popper e Bachelard. Teve sua primeira publicação em alemão no ano de 1935, mas somente em 1962 apareceu a primeira menção à sua obra no prefácio do livro de Thomas Kuhn, A Estrutura das Revoluções Científicas, no qual o físico norte-americano afirmou que a obra de Fleck é um ensaio que antecipa muitas ideias encontradas em seu próprio livro. Esse fato foi decisivo para que a obra de Fleck saísse da obscuridade. Posteriormente, em 1979, Kuhn faz a apresentação da versão em inglês do livro (FLECK, 1979).

Suas ideias vêm sendo utilizadas de modo crescente no país. Levantamentos realizados por Lorenzetti (2008) indicam a existência de centros de estudos no Brasil que utilizam Fleck como referência, mostrando que sua obra e sua utilização em pesquisas nacionais apresentam uma trajetória e uma aplicação em diferentes contextos. Destacam-se, particularmente, os trabalhos de Da Ros (2000), Slongo (2004), Delizoicov (2004), Lorenzetti (2008) e Slongo e Delizoicov (2010), que analisam a produção de conhecimentos contemporâneos, tais como os que são objeto de análise neste artigo. 
Fleck (1986) propõe que o processo de conhecimento deve se realizar na interação do sujeito com o objeto, mediado pelo que ele denomina de estilo de pensamento e no interior de um coletivo de pensamento.

O estilo de pensamento é o direcionador do modo de pensar e de agir de um grupo de pesquisadores de uma determinada área do conhecimento. O coletivo de pensamento pode ser compreendido como uma "comunidade de indivíduos que compartilham práticas, concepções, tradições e normas” (LEITE et al., 2001), no qual a maneira própria de ver o objeto do conhecimento e de interagir com ele determina o estilo de pensamento.

A circulação do conhecimento pode ser considerada como um dos aspectos centrais do pensamento epistemológico fleckiano. $\mathrm{Na}$ estrutura geral do coletivo de pensamento, Fleck (1986) distingue os círculos esotérico e exotérico. A presença de um círculo esotérico, formado por especialistas de uma determinada área do conhecimento, caracteriza a identidade primeira do coletivo de pensamento, por ser o portador do estilo de pensamento. É a partir desse núcleo de conhecimentos e de práticas compartilhadas que se forma o círculo exotérico, formado por leigos e leigos formados, quando passam a interagir, por meio de múltiplas alternativas, com o círculo esotérico.

Entre os círculos exotérico e esotérico são estabelecidas relações dinâmicas que contribuem para a ampliação e disseminação do conhecimento, denominadas circulação intracoletiva e intercoletiva de ideias. A circulação intracoletiva de ideias ocorre durante a formação dos membros do coletivo que compõem o circulo esotérico, de tal modo que ao compartilhar ideias, conhecimentos e práticas, contidas no estilo de pensamento, possam produzir novos conhecimentos que passam a ser incorporados ao estilo de pensamento. Já a circulação intercoletiva propicia a extensão do estilo de pensamento para o círculo exotérico, auxiliando a compreender a interação entre o círculo esotérico e exotérico.

$\mathrm{Na}$ presente pesquisa, a própria constituição do grupo de investigadores é objeto de análise, a fim de que a produção dos seus conhecimentos e práticas seja caracterizada. Assim, através de análise documental, realizou-se tanto o resgate histórico da produção desse grupo como a retomada de aspectos que fundamentaram teórica e praticamente a gênese e proposição dos 3MP. Essa análise teve como referência aspectos teóricos e dados de práticas contidos em dissertações, teses, livros e artigos. Dentre as obras consultadas estão: ANGOTTI (1982; 1991), DELIZOICOV (1980; 1982; 1991), PERNAMBUCO (1981; 1993; 1994), PERNAMBUCO et al. (1988), SÃO PAULO (1990; 1992), BRASIL (1994).

\section{RESULTADOS E DISCUSSÃO}

A partir de uma reflexão acerca dos projetos desenvolvidos e analisados na Guiné Bissau (Delizoicov 1980, 1982; Angotti, 1982), no Rio Grande do Norte (PERNAMBUCO, 1981; 1993; 1994) e no município de São Paulo (SÃO PAULO, 
1990; 1992), procura-se compreender as origens, os pressupostos teóricos e as diferentes formas de utilização da dinâmica dos 3MP.

\section{INSTITUTO DE FÍSICA DA UNIVERSIDADE DE SÃO PAULO (IFUSP): INSTAURAÇÃO DE UMA CONCEPC̣ÃO PARA O ENSINO DE CIÊNCIAS}

Diante da indagação “Como tudo começou?”, é possível localizar o Instituto de Física da Universidade de São Paulo (IFUSP), onde por volta de 1975 discutia-se uma proposta para o ensino de Ciências que tinha entre seus objetivos a compreensão do mundo físico em que o estudante vivia (MENEZES, 1988; 1996).

Dentre os participantes dos encontros/discussões, estavam os professores Luís Carlos de Menezes, João Zanetic e os então alunos de pós-graduação Demétrio Delizoicov e José André Angotti (PIERSON, 1997).

De acordo com Delizoicov (1982), a familiaridade da concepção em discussão no IFUSP com a concepção educacional de Paulo Freire motivou o grupo a utilizá-la ou adaptá-la a um contexto de educação formal em Ciências.

Assim, Demétrio Delizoicov e Nadir Castilho, seguidos por José André Angotti e Isaura Simões, adaptaram pela primeira vez o que havia sido discutido na USP, ou seja, a concepção freiriana num contexto de educação formal. Isso ocorreu na distante Guiné-Bissau, onde Freire já estivera (ZANETIC, 1989).

Essa atuação educacional, que foi desenvolvida através do projeto "Formação de professores de Ciências Naturais", é relatada e analisada por Delizoicov (1982) e Angotti (1982) em seus trabalhos de mestrado. Convém destacar que o estabelecimento desse projeto se deu em um contexto que tentava garantir escolarização básica de seis anos para todas as crianças e adolescentes do país e preparar os jovens para a vida nas comunidades rurais ${ }^{3}$.

As primeiras discussões do grupo, ainda no IFUSP, sobre a transposição da concepção freiriana para a educação escolar, estavam em sintonia com a instauração de uma concepção para o ensino de Ciências. Pode-se reconhecer em suas preocupações - que, sinteticamente, se resumem na questão relatada por Zanetic (1989): "não deveria ser apresentada na escola uma Física mais próxima do mundo que nos cerca?" - as razões e objetivos dos diferentes trabalhos que foram e vêm sendo desenvolvidos pelo grupo ao longo dos anos, no qual o pensamento do educador Paulo Freire tem sido uma referência constante.

\section{INSTAURAC̣ÃO DE PRÁTICAS EDUCATIVAS FREIRIANAS: ORIGEM DOS TRÊS MOMENTOS PEDAGÓGICOS}

Com o desenvolvimento do Projeto de ensino de Ciências Naturais na Guiné-Bissau (DELIZOICOV, 1980; ANGOTTI, 1981), foi possível estabelecer o 
que hoje se denomina de 3MP, inicialmente denominado "roteiro pedagógico" (DELIZOICOV, 1982, 1991).

Esse roteiro já era utilizado pelo Centro de Educação Popular Integrada (CEPI), coordenado pelo Institut de Recherché, Formation e Developpement (IRFED) em parceria com o Ministério da Educação da Guiné Bissau . Esse centro, criado em 1977, era um modelo de escola de $5^{\mathrm{a}}$ e $6^{\mathrm{a}}$ séries do $1^{\mathrm{o}}$ grau, voltada para o meio rural e também um centro de formação de professores. Dentre suas preocupações estavam a ligação com a comunidade e a vinculação dos alunos ao seu meio sociocultural (BOMBOLON, 1980).

Conforme caracteriza Delizoicov (1982), no CEPI o trabalho escolar era organizado em três momentos: Estudo da Realidade, Estudo Científico e Trabalho Prático. O Estudo da Realidade correspondia ao primeiro contato com o assunto a ser estudado, fosse por meio de "exame do objeto em estudo" ou do levantamento de dados. Inúmeras atividades poderiam ser realizadas com a finalidade de melhor entender os meios produtivos e as relações de produção do meio rural guineense, tais como: observação dirigida de uma planta ou animal, debate entre os alunos sobre problemas existentes, entrevistas com a população e representantes das instituições oficiais sobre o desenvolvimento da região, entre outros. O segundo momento, Estudo Científico, era o momento de se abordar aspectos necessários à compreensão da realidade, de modo a incorporar o desenvolvimento do espírito científico, de habilidades de cálculo, manuseio de instrumentos, estímulo no uso da língua portuguesa, uso do dicionário, capacidade de síntese, entre outros. E o Trabalho Prático, correspondente ao terceiro momento, consistia na realização de atividades coletivas estimuladas pelo estudo científico e articuladas a intervenções que se relacionavam com as condições locais em que a população vivia. Nessa etapa, construções de latrinas, produção de sabão, elaboração de cartazes mobilizadores, conservação do espaço escolar, atividades culturais com a finalidade de resgatar e valorizar a cultura das etnias locais eram algumas das atividades propostas (BOMBOLON, 1980).

É possível, portanto, considerar que as interações ocorridas nesse processo caracterizam-se como circulação de ideias e práticas (FLECK, 1986) entre educadores guineenses e seus formadores, que estavam cooperativamente implementando ações educativas, cujo resultado foi o estabelecimento de práticas em construção que viriam a ser compartilhadas por um coletivo, como é o caso do roteiro pedagógico que deu origem aos $3 \mathrm{MP}$ ao longo da implementação do Projeto de ensino de Ciências Naturais na Guiné-Bissau, a partir de adequações realizadas nos momentos pedagógicos adotados no CEPI.

\section{EXTENSÃO DE PRÁTICAS EDUCATIVAS: AS PRIMEIRAS MUDANC̣AS NO ROTEIRO PEDAGÓGICO NA GUINÉ-BISSAU}

Nessa primeira aplicação do roteiro pedagógico, implementada por Demétrio Delizoicov e Nadir Castilho na formação dos professores guineenses, chama a 
atenção algumas transformações na proposição inicial do CEPI, que contribuíram para a constituição de conhecimentos e práticas daquele grupo de investigadores, mais precisamente por Demétrio Delizoicov, José André Angotti e, posteriormente, pelas contribuições de Marta Pernambuco.

Nas características do CEPI há uma inspiração teórico-crítica, mesmo que não esteja vinculada à perspectiva freiriana de educação. Dentre as bases para sua elaboração pedagógica, encontra-se a apropriação do saber científico com a perspectiva de preparar os alunos para a compreensão e análise crítica das condições locais em que vive a população para uma atuação com vistas à sua transformação.

Conforme as palavras de Delizoicov (1991: 184) acerca do roteiro pedagógico, "pudemos construí-lo criticamente e usá-lo nas atividades e textos produzidos e empregados nas salas de aula...", é possível perceber que uma construção crítica foi possível. Entende-se que muito além de uma simples troca de nomenclatura do terceiro momento, ou seja, de trabalho prático para aplicação do conhecimento, existem grandes diferenças no roteiro pedagógico criado pelo CEPI e no construído, ou melhor, reconstruído, na prática implementada pelo projeto "Formação de Professores de Ciências da Guiné Bissau".

No primeiro momento pedagógico, para dar encaminhamento aos debates, questões foram propostas. Enfatizou-se o papel ativo do aluno, assim como a função do educador de encaminhar os debates.

Já no segundo momento pedagógico, de modo semelhante ao que ocorria no CEPI, a abordagem dos conhecimentos científicos necessários à compreensão de situações significativas oriundas do local em que vivia a população era desenvolvida. Não obstante essa semelhança, destacam-se pressupostos teóricos que embasavam a fundamentação do segundo momento, o que pode ser caracterizado como conhecimentos compartilhados pelo grupo, particularmente em relação ao papel do educador científico. Delizoicov, Angotti e Pernambuco, ao refletirem sobre o diálogo tradutor, que implica num processo para obtenção do conhecimento do senso comum dos educandos, enfatizam:

[...] é para problematizá-lo que o professor deve apreender o conhecimento já construído pelo aluno; para aguçar as contradições e localizar as limitações desse conhecimento, quando cotejado com o conhecimento científico, com a finalidade de propiciar um distanciamento crítico do educando, ao se defrontar com o conhecimento que ele já possui, e, ao mesmo tempo, propiciar a alternativa de apreensão do conhecimento científico (2002: 199).

Em outras palavras, buscava-se a desestabilização/desestruturação das explicações dos estudantes para, logo após, formular problemas que pudessem levar os estudantes à compreensão do conhecimento científico.

O terceiro momento pedagógico, denominado Aplicação do Conhecimento, é considerado a primeira transformação do roteiro pedagógico, segundo considerações de Delizoicov $(1982,1991)$ a partir do que havia sido implementado pelo CEPI. Para além da mudança de nome, verifica-se que não apenas as produções, construções de equipamentos, elaboração de cartazes foram analisados durante a 
aplicação. Constata-se um retorno para a discussão do que é proposto inicialmente no primeiro momento, ou seja, um retorno às questões iniciais assim como a proposição de novas questões que possam ser respondidas pela mesma conceituação científica abordada no segundo momento, na intenção de transcender o uso do conhecimento para outras situações que não apenas a inicial.

Nesse sentido, constatam-se transformações/recriações quanto à finalidade e uso dos momentos acima explorados. A intenção dos formadores era garantir a presença constante de análises e sínteses dos conhecimentos, através do processo dialógico expresso nas falas dos educandos e educadores. No que tange às expectativas, Delizoicov manifesta conhecimentos compartilhados pelo grupo de pesquisadores:

A expectativa era que, qualitativamente, cada um dos momentos fosse diferente, propiciando num crescente, de um lado, a apropriação do conteúdo programático pelo educando e, de outro, o seu uso e aproximação de situações reais e vividas por ele. [...] Uma dinâmica que partindo do concreto, do real vivido, a ele retorna, mas como "outro" concreto, na medida em que entre o "primeiro" e o "segundo" concreto, se estaria garantindo a abstração necessária para sua reinterpretação, via conhecimentos científicos selecionados, constituídos em conteúdos programáticos escolares (DELIZOICOV, 1991: 184).

Nesse projeto, quando se trata da reconstrução dos 3MP, entende-se que o principal avanço com relação à proposição inicial é a incorporação da dialogicidade em cada um dos três momentos. Assim a perspectiva do uso sistemático da dialogicidade, conforme fundamentada por Freire (1987), é parte constituinte das concepções teóricas compartilhadas pelo grupo. A coerência com o referencial na tentativa de adaptar a concepção freiriana para um contexto de educação formal parece ter sido buscada, estruturando o compromisso do grupo.

Com relação às primeiras mudanças no roteiro pedagógico, constata-se que existem diferenças no que foi criado pelo CEPI e no reconstruído na prática. Esse roteiro pode ser considerado como a gênese do que hoje se denomina 3MP. A circulação de ideias (FLECK, 1986), mediatizada pelas interações entre os membros da equipe do Projeto Formação Continuada de Professores de Ciências Naturais da Guiné Bissau com membros da equipe CEPI, potencializou, de um lado, uma opção para se obter e problematizar o conhecimento prevalente de alunos, relativos às situações significativas que são abstraídas dos contextos em que vivem; de outro, a inserção de conhecimentos científicos, com o auxílio estruturante dos conceitos unificadores (ANGOTTI, 1982, 1991) na sua articulação com as situações estudadas, propiciando alternativas didáticas que estavam sendo incorporadas aos conhecimentos e práticas constituintes do coletivo de pesquisadores em ensino de Ciências investigados neste artigo. 


\section{EXTENSÃO DE PRÁTICAS EDUCATIVAS: O APROFUNDAMENTO DO SIGNIFICADO DO ROTEIRO PEDAGÓGICO NO DECORRER DO PROJETO DO RIO GRANDE DO NORTE}

Foi no projeto Ensino de Ciências a Partir de Problemas da Comunidade (PERNAMBUCO, 1983), desenvolvido a partir de 1984 no Rio Grande do Norte, que o roteiro pedagógico, ao ser utilizado em outro contexto, foi objeto de análise a partir de parâmetros não considerados anteriormente. Os pesquisadores envolvidos no projeto eram quatro físicos-educadores: Marta Pernambuco, Cristina Dal Pian, José André Angotti e Demétrio Delizoicov, todos colegas da época do mestrado em Ensino de Ciências na USP, assessorados por estudantes da área de Sociologia e Antropologia, além de professoras de Biologia que haviam participado do projeto da Guiné Bissau. As reflexões sobre a utilização do roteiro nesse projeto permitiram um aprofundamento do seu significado (PERNAMBUCO, 1994; PERNAMBUCO et al., 1988).

Dentre as novas modificações, está a denominação do segundo momento pedagógico, o Estudo Científico. Houve a compreensão de que essa nomenclatura não era a mais adequada, pois os outros momentos, especialmente o terceiro, não eram "menos científicos" que o segundo momento pedagógico. Assim, se passou a denominá-lo Organização do Conhecimento (DELIZOICOV, 1991). Para Delizoicov, essa modificação não representou apenas uma mudança de denominação, já que "permitiu um salto qualitativo na nossa própria percepção do trabalho até então realizado" (DELIZOICOV, 1991: 185).

Conforme Delizoicov (1991), antes de dar início ao projeto do Rio Grande do Norte, não estava claro que os momentos pedagógicos poderiam ser empregados também no estabelecimento de uma sequência programática pois, até então, apenas haviam servido para estruturar dinâmicas de sala de aula ${ }^{5}$.

Pernambuco (1993), ao destacar a postura dialógica dos 3MP, comenta que estes se aplicam tanto para a organização dos temas, dentro da organização mais geral do programa, quanto para a organização das atividades de sala de aula. A autora descreve como os professores realizam o trabalho, enfatizando que a partir dos três organizadores ${ }^{6}$, os professores reunidos por série e por área retomam as questões geradoras ${ }^{7}$ gerais propondo questões de cada série e, dentro de cada série, de cada área. A seguinte afirmação contribui para uma reflexão nesse sentido:

\footnotetext{
As questões da série, portanto comuns a todas as áreas, apontam os momentos iniciais e finais da programação, ou seja, o estudo da realidade (ER) e a aplicação do conhecimento (AC). As necessidades geradas pelo momento de estudo da realidade são respondidas pelas diferentes áreas e devem estar indicadas nas questões de cada área. As questões de área apontam, portanto, os conhecimentos disponíveis a serem apreendidos na organização do conhecimento (OC)" (PERNAMBUCO, 1993: 91).
}

Pernambuco enfatiza que nesse trabalho conjunto dos educadores surge, de um lado, o prazer de perceber os pontos comuns que estão sendo trabalhados e como que, juntando forças, é possível "catalisar" o surgimento de habilidades 
que muitos se esforçavam para obter de forma isolada. De outro, a dificuldade de abrir mão de conhecimentos considerados como sendo de uma única área, que são "partilhados" por outras, de reformular sequências programáticas consideradas, em absoluto, como necessárias.

Frente ao exposto, destaca-se que as interações internas do grupo, no enfrentamento da construção de práticas educativas em sintonia com a perspectiva freiriana, representam um importante papel no seu processo de produção. Ou seja, a partir da circulação intracoletiva (FLECK, 1986), no contexto do projeto "Ensino de Ciências a Partir de Problemas da Comunidade", o grupo adquiriu conhecimentos e estabeleceu práticas, como é o caso dos $3 \mathrm{MP}$, que foram empregados no estabelecimento de uma sequência programática, isto é, como estruturadores de um currículo, e por isso considerados um "salto" (DELIZOICOV, 1991) na percepção do coletivo. Pode-se dizer que o projeto do Rio Grande do Norte contribuiu para uma ampliação das ideias do grupo, não apenas relacionadas ao nível das práticas, mas em um "movimento articulado de prática com elaboração teórica” (PERNAMBUCO, 1994).

Diante dessa recuperação histórica, enfatiza-se que no decorrer dos projetos "Formação de professores de Ciências Naturais" e "Ensino de Ciências a partir de problemas da comunidade" constitui-se esse grupo de pesquisadores, ou seja, um círculo esotérico (FLECK, 1986) cujos conhecimentos e práticas são decorrentes do enfrentamento do problema da transposição da concepção de Paulo Freire para o ensino de Ciências na educação escolar. Parte do processo que caracteriza a produção desse círculo diz respeito à construção e proposição dos $3 \mathrm{MP}$, objeto de análise neste artigo. Conforme se destacou, durante a circulação de ideias, conhecimentos e práticas ocorridas nas interações estabelecidas pelo grupo, ocorreram transformações durante a construção dos 3MP.

A partir desse resgate histórico, é possível enfatizar também que foi no decorrer do projeto "Formação de professores de Ciências Naturais" que ocorreu a incorporação, pelo círculo esotérico, dos 3MP ao processo de investigação temática (FREIRE, 1987). Sabendo que os 3MP encontram-se inseridos numa concepção transformadora da educação, torna-se imprescindível aprofundar sua relação com a construção do currículo escolar. Para isso, faremos uma análise de como os 3MP foram disseminados na prática durante o Movimento de Reorientação Curricular do município de São Paulo (PONTUSCHKA, 1994; SAMPAIO, QUADRADO, PIMENTEL, 1994; FREIRE, 1995; TORRES, O'CADIZ E WONG, 2002) entre os anos de 1989 e 1992, uma vez que envolveu a construção de currículos nos quais estavam contidos, dentre outros aspectos, conhecimentos das várias disciplinas que compõem programas de ensino da Educação Fundamental. 


\section{OS MOMENTOS PEDAGÓGICOS NA CONSTRUC̦ÃO DO CURRÍCULO NO PROJETO INTERDISCIPLINAR DO MUNICÍPIO DE SÃO PAULO: O PAPEL DA CIRCULAÇÃO INTERCOLETIVA}

O Projeto Interdisciplinar do município de São Paulo, também chamado Projeto "Interdisciplinaridade via Tema Gerador" ou Projeto Inter, ocorrido entre 1989-1992, quando o próprio educador Paulo Freire foi secretário da educação da capital paulista (FREIRE, 1995), teve efeitos significativos sobre o currículo, o ensino e a formação de professores (TORRES, O’CADIZ E WONG, 2002). Nesse sentido, torna-se fundamental aprofundar a conexão dos momentos pedagógicos com o processo de construção curricular presente nesse projeto.

De acordo com Torres, O’Cadiz e Wong (2002), os 3MP estavam implícitos em todos os aspectos pedagógicos do Projeto Inter, ou seja, orientavam tanto o desenvolvimento curricular geral como o trabalho específico de sala de aula. A implementação dos momentos pedagógicos como planejamento curricular variava de NAE (Núcleo de Ação Educativa) para NAE e em cada escola, dependendo das interpretações e das distintas linhas de orientação gerais do projeto.

Sampaio, Quadrado e Pimentel, ao investigarem o Projeto Inter por meio de um estudo de caso para o INEP, enfatizam:

A nova metodologia de trabalho, que introduz abertura para a participação integrada dos educadores e também de alunos e comunidade, instala-se desde o início, quando ocorre o Estudo da Realidade Local, primeira etapa do projeto (BRASIL, 1994: 58).

\section{a) Estudo da Realidade (ER): a primeira etapa do desenvolvimento curricular - 0 estudo da realidade local}

A primeira fase do desenvolvimento curricular exigia que a comunidade escolar, apoiada por uma equipe, se envolvesse em uma investigação preliminar da realidade para decidir quais as "situações significativas", ou seja, quais as circunstâncias sociais, culturais e políticas constituíam o mundo vivido. As escolas organizavam os dados recolhidos na forma de um "dossiê" que ilustrava a realidade local da escola (TORRES, O’CADIZ e WONG, 2002).

Durante esse período, os educadores tornavam-se "observadores participantes" da realidade da escola. As entrevistas e inquéritos aos alunos, pais e residentes locais constituíram o principal meio de "recolha" de dados ${ }^{8}$ durante essa primeira fase, ou seja, o ER da planificação curricular (TORRES, O’CADIZ E WONG, 2002).

Uma vez colhidos e registrados os dados da realidade, o passo subsequente era "codificar" ou "categorizar" as falas (entrevistas registradas) e as informações adicionais". Esse processo de categorização era "coletivo e interdisciplinar", procurando garantir um equilíbrio entre objetividade e subjetividade e a ligação entre o particular e o social, criando uma visão abrangente da realidade (SÃO PAULO, Caderno de Formação no 2, 1990: 38-39). 
Como consequência desse processo, interativo e dinâmico, de análise conjunta, eram identificadas várias situações significativas e chegava-se a um consenso sobre os temas geradores em torno dos quais o currículo seria construído (TORRES, O’CADIZ E WONG, 2002).

Esse diálogo inicial entre escola e comunidade/educador e educando, na fase chamada ER, levava ao segundo e terceiro momentos do processo de desenvolvimento curricular e da prática pedagógica de sala de aula do Projeto Inter.

\section{b) Organização do Conhecimento (OC): a segunda etapa do desenvolvimento curricular - 0 tema gerador}

Nessa fase, os educadores que trabalhavam no currículo interdisciplinar via tema gerador utilizavam os dados e as informações do Estudo da Realidade para construírem as questões geradoras para cada uma de suas áreas disciplinares, a partir das quais se determinavam os conteúdos específicos a ensinar em cada série/ciclo.

Os temas geradores, propostos como um caminho para reorientar de forma interdisciplinar o currículo, eram compreendidos como objetos de estudo que compreendiam "o fazer e o pensar, a ação e a reflexão, a teoria e a prática" (SAMPAIO, QUADRADO E PIMENTEL, 1994:59).

Para contribuir nessa fase, a Secretaria da Educação de São Paulo articulou a noção de conceitos unificadores, proposta por Angotti (1991), que eram desenvolvidos para cada área disciplinar. De acordo com o Documento 5 - Visão de Área: Ciências, produzido pela Secretaria Municipal de Educação com o objetivo de ampliar a discussão sobre o ensino de Ciências Naturais nas escolas e propor parâmetros para a construção de programas escolares, a abordagem por conceitos unificadores, além de garantir "um referencial para seleção dos conteúdos escolares", permitia o tratamento de questões contemporâneas que usualmente não constavam nos currículos escolares (SÃO PAULO, 1992).

\section{c) Aplicação do Conhecimento (AC): a terceira etapa do desenvolvimento curricular - a implementação e avaliação do programa}

A terceira e última etapa, a Aplicação do Conhecimento, representava a implementação e avaliação do programa e o planejamento de atividades que demonstrassem as construções do conhecimento. De acordo com Torres, O’Cadiz e Wong (2002), como primeiro passo dessa etapa os professores decidiam "a forma de avaliar a aquisição por parte dos alunos dos conceitos ensinados” (2002: 148).

A construção geral do programa envolvia, portanto, um processo contínuo de ação e reflexão, baseado nos $3 \mathrm{MP}$ (ER - OC - AC). O Projeto Inter começava com a fase inicial de problematização da realidade, seguia com a organização da informação registrada na fase inicial e finalmente esta era sintetizada na fase de aplicação do conhecimento, com a realização de atividades concretas que visassem demonstrar a aquisição de conhecimentos por parte dos educandos. Enfim, pode-se afirmar que os momentos pedagógicos constituíram a base pedagógica do Projeto Inter na transformação do currículo. 
Destaca-se, portanto, que a disseminação do uso dos 3MP, ocorrida com a implantação do Projeto Inter por educadores da rede municipal de educação de São Paulo, através da circulação intercoletiva (FLECK, 1986) originada de processos formativos planejados, possibilitou uma extrapolação diferenciada do seu uso inicial, proposto e usado nos dois projetos anteriores. Durante o projeto desenvolvido em São Paulo, os 3MP estruturaram tanto o processo de investigação temática e redução temática (FREIRE, 1987) quanto passaram a ser usados na dinâmica didático-pedagógica das aulas de outras disciplinas escolares, além de Ciências, como originalmente ocorreu. Pernambuco $(1993,1994)$ e Delizoicov, Angotti e Pernambuco (2002a) aprofundam e exemplificam o papel dos 3MP como estruturador do planejamento de ações que envolvem coletivos, em seções de trabalho que se ocupam de processos formativos, particularmente de professores em serviço, e na elaboração de planos de ensino e de aula.

\section{CONSIDERACְÕES FINAIS}

Levando em consideração a teoria do conhecimento formulada por Fleck (1986), a presente investigação buscou compreender a dinâmica da produção do círculo esotérico e da circulação de ideias que originou e implementou os 3MP (ANGOTTI, 1982; 1991, DELIZOICOV, 1980; 1982; 1991, PERNAMBUCO, 1981; 1993; 1994 , PERNAMBUCO et al. 1988, SÃO PAULO 1990; 1992, BRASIL, 1994).

O grupo de investigadores no ensino de Ciências, que propôs os $3 \mathrm{MP}$, inicialmente formado por Delizoicov e Angotti, voltou a atenção ao ensino de $1^{\circ}$ grau, no projeto desenvolvido na Guiné Bissau (DELIZOICOV, 1980; ANGOTTI, 1981) que, como vimos, foi um importante momento de sistematização e concretização das ideias de Paulo Freire em um contexto de educação formal (DELIZOICOV,1982, 1983, 1991; ANGOTTI, 1982, 1991). Posteriormente, juntaram-se ao grupo Pernambuco e Dal Pian, no projeto desenvolvido no Rio Grande do Norte (PERNAMBUCO, 1983). Em ambos os projetos, e posteriormente no trabalho desenvolvido na Secretaria Municipal de Educação da cidade de São Paulo (PONTUSCHKA, 1994; SAMPAIO, QUADRADO, PIMENTEL, 1994; FREIRE, 1995; TORRES, O’CADIZ E WONG, 2002), quando Alice Pierson e João Zanetic juntaram-se ao grupo, percebe-se a presença das ideias do educador Paulo Freire, principalmente com relação às categorias dialogicidade e problematização.

Pode-se considerar, portanto, que as discussões do grupo, ainda no IFUSP (MENEZES, 1988; 1996; ZANETIC, 1989), sobre a transposição da concepção freiriana para a educação escolar, estavam se constituindo num círculo esotérico (FLECK, 1986) através de circulação intracoletiva de ideias (FLECK, 1986), mediada pelo estudo e interpretação de obras de Paulo Freire. Sua concepção de educação e de conhecimento, associada à formulação de problemas de pesquisa (DELIZOICOV, 2008) relacionados às principais categorias que o educador emprega, propiciou a mediação das interlocuções no interior do grupo e a busca de estratégias para o enfrentamento dos desafios. 
Pernambuco (1994) aponta a possibilidade de utilizar a dinâmica dos 3MP das mais variadas formas, inclusive não previstas na sua elaboração original. Assim, destaca: folhetos de divulgação de campanhas públicas, recortes de jornais, reportagens ou programas de TV, depoimentos e entrevistas, textos didáticos, enciclopédias, textos de divulgação, literatura, originais de autores, artigos científicos, histórias em quadrinhos, músicas, organização de reuniões, e para planejar o trabalho em cursos de formação.

Ao longo dos anos, os 3MP foram sendo revistos e extrapolaram sua utilização inicial, tornando-se um parâmetro para o processo como um todo, fundamentalmente pelo aspecto dinâmico. Assim, pode-se, hoje, destacar mais uma utilização não conjecturada inicialmente, que é a elaboração de material didático para cursos de graduação à distância (livro do aluno ${ }^{10}$ ) e a utilização como estruturadores/ organizadores das discussões em eventos ${ }^{11}$, além da proposição e publicação dos livros Física (DELIZOICOV e ANGOT'TI, 1992) e Metodologia do Ensino de Ciências (DELIZOICOV e ANGOTTI, 1994) e Ensino de Ciências: Fundamentos e Métodos (DELIZOICOV, ANGOTTI, PERNAMBUCO, 2002). Diante dessa recuperação histórica, percebe-se que a participação do estudante e o seu cotidiano assumem um papel de destaque na prática educativa que utiliza os 3MP, proporcionando à educação um avanço no que se refere ao ensino tradicional.

Por outro lado, conforme foi destacado (DELIZOICOV, 2008), é necessário ficar alerta quanto a um uso que reduz os $3 \mathrm{MP}$ a uma estratégia didática apenas, que estaticamente organiza as aulas de modo que o primeiro momento seja um simples pretexto e justificativa para se introduzir, no segundo, determinada conceituação científica e, no terceiro, a solução de exercícios e problemas. Conforme o resgate histórico-epistemológico apresentado, trata-se de uma prática didático-pedagógica que, tendo como fundamentos a dialogicidade e a problematização, conforme consideradas por Freire (1987), possibilita a presença constante e sistematizada de elementos de situações significativas oriundas do local em que vive a população que envolvem contradições, para que sejam sistemáticas as problematizações das compreensões dos alunos sobre elas, obtidas através das suas "falas". A meta pretendida com os 3MP, tanto como dinâmica de sala de aula, como estruturador que parametriza currículos e programas de ensino, constitui um desafio para docentes, uma vez que se pretende localizar limitações nas compreensões, tanto de alunos, ao se expressarem sobre as situações, como de professores, que as têm como um dos componentes do processo educativo para que, em uma dinâmica que promova a conscientização, se implementem conhecimentos e práticas anteriormente ausentes em processos educativos escolares e em outras práticas socioculturais.

\section{NOTAS}

\footnotetext{
${ }^{1}$ Uma versão preliminar dessa pesquisa, intitulada "Os três momentos pedagógicos: um olhar histórico-epistemológico”, foi apresentada em sessão especial do XII Encontro de Pesquisa em Ensino de Física (EPEF), realizado de 24 e 28 de outubro de 2010, em Águas de Lindóia/SP.
} 
${ }^{2}$ Como, por exemplo, os realizados e analisados na Guiné Bissau (Delizoicov, 1982), no Rio Grande do Norte (Pernambuco, 1981; 1993; 1994) e no município de São Paulo (São Paulo, 1990; 1992).

${ }^{3}$ Torna-se relevante enfatizar que a população da Guiné-Bissau era eminentemente rural, pois dos 800.000 habitantes da época, $85 \%$ viviam nesse meio. O projeto foi considerado de emergência, devido à falta de professores, o que não substituiu a formação de nível superior (DELIZOICOV, 1982; 1983).

${ }^{4} \mathrm{Na}$ época denominado de Comissariado da Educação Nacional - CEN.

${ }^{5}$ Segundo Delizoicov (1991), foi também a partir desse projeto que a utilização dos três momentos pedagógicos para planejar o trabalho das equipes em cursos de formação de professores começou a ser refletida.

${ }^{6}$ Como organizadores, os três momentos não se distinguem necessariamente no tempo, constituindo atividades separadas. São uma maneira de refletir aonde se quer chegar e qual rumo se pode dar ao trabalho em cada momento (PERNAMBUCO, 1994).

${ }^{7}$ As questões geradoras têm a finalidade de explicitar "para quem" e "o que dos múltiplos aspectos que envolvem os temas geradores" serão considerados como proposta de trabalho para a escola, para cada série, para cada área do conhecimento. Dentre os objetivos das questões geradoras, destacam-se: dar continuidade à problematização dos temas geradores; gerar conteúdos que favoreçam desocultar as contradições da realidade implícitas na temática; articular os conteúdos propostos; direcionar as respostas para o lugar aonde os educadores querem chegar (SÃO PAULO, 1990).

${ }^{8}$ Dados reforçados por sondagens a empresas, clínicas e outros órgãos locais, assim como por observações gerais recolhidas juntamente com documentações secundárias, como dados estatísticos sobre a área, artigos de imprensa e outra literatura relevante.

${ }^{9}$ Como “fotografias, vídeos, estatísticas demográficas e outra informação proveniente de documentos formais sobre as características econômicas, políticas e socioculturais” (TORRES, O’CADIZ e WONG, 2002: 144).

${ }^{10}$ Cf.: Disciplina Didática Geral do curso de Licenciatura em Física a Distância da UFSC. DELIZOICOV, D.Didática Geral. Florianópolis: UFSC/EAD/CED/CFM, 2008.

$119^{\circ}$ Fórum de Estudos: Leituras de Paulo Freire, ocorrido em maio de 2007, na cidade do Rio Grande/RS.

\section{REFERÊNCIAS BIBLIOGRÁFICAS}

ANGOTTI, J.A. (1981) Rapport sur le projet de formation des professeurs de sciences naturelles en Guiné Bissau: Bilan 1979-1981. Paris: IRFED, 1981.

- Solução alternativa para a formação de professores de ciências: um projeto educacional desenvolvido na Guiné-Bissau. 1982. Dissertação (Mestrado). São Paulo - Instituto de Física da Universidade de São Paulo (IFUSP), Faculdade de Educação da Universidade de São Paulo ( FEUSP), São Paulo, 1982.

. Fragmentos e totalidades no conbecimento cientifico e no ensino de ciências. 1991. Tese (Doutorado).

Instituto de Física da Universidade de São Paulo (IFUSP), Faculdade de Educação da Universidade de São Paulo (FEUSP), São Paulo, 1991. 
BRASIL, INSTITUTO NACIONAL DE ESTUDOS E PESQUISAS EDUCACIONAIS. Interdisciplinaridade no município de São Paulo. Brasília: Série Inovações Educacionais: INEP, 1994.

BOMBOLON - Revista do CEPI. (1980 out). Bissau, nº (mimeografado).

DA ROS, M. A. Estilo de pensamento em educação médica: um estudo da produção da FSP-USP e ENSPFIOCRUZ entre 1948 e 1994, a partir de epistemologia de Ludwik Fleck. 2000. Tese (Doutorado em Educação) - Universidade Federal de Santa Catarina, Florianópolis, 2000.

DELIZOICOV, D. (1980). Rapport sur le projet de formation des professeurs de sciences naturelles en Guiné Bissau: Bilan 1979-1980. Paris: IRFED, 1980.

. Uma experiência em ensino de ciências na Guiné Bissau Depoimento. Revista de Ensino de Física,São Paulo, v.2, n.4. Dez. 1980

- (1982). Concepção problematizadora do ensino de ciências na educação formal. Dissertação de mestrado. São Paulo: IFUSP/FEUSP.

. Ensino de Física e a Concepção Freiriana de Educação. Revista de Ensino de Física, São Paulo, vol. 5, n.2. Dez. 1983.

. (1991). Conhecimento, tensões e transições. Tese (Doutorado) - Faculdade de Educação da Universidade de São Paulo, 1991. FEUSP.

- (2004). Pesquisa em ensino de ciências como ciências humanas aplicadas. Caderno Brasileiro de Ensino de Física, Florianópolis, v. 21, n. 2. 2004'

- (2008). La Educación en Ciencias y la Perspectiva de Paulo Freire. Alexandria Revista de Educação em Ciência e Tecnologia, v.1, n.2, p.37-62. Disponível em:<http://alexandria.ppgect.ufsc. br//numero_2/artigos/demetrio.pdf > . Acesso em: 10 jan., 2011.

; ANGOTTI, J.A. Física. São Paulo: Cortez,1992.

; ANGOTTI, J.A. Metodologia do ensino de ciências. São Paulo: Cortez, 1994.

; ANGOTTI, J. A.; PERNAMBUCO, M.M. Ensino de Ciências: fundamentos e métodos.

São Paulo: Cortez, 2002.

; ANGOTTI, J. A.; PERnAMBUCO, M.M. (2002a). Temas de ensino e escola. In: ; ANGOTTI, J. A.; PERNAMBUCO, M.M. Ensino de Ciências: fundamentos e métodos.

São Paulo: Cortez, 2002.

FLECK, L. La génesis y el desarrollo de un hecho científico. Madrid: Alianza, 1986.

Fleck, L. Genesis and Development of a Scientific Fact. Chicago: University of Chicago Press, 1979.

FREIRE, P. Pedagogia do Oprimido. 17. ed. Rio de Janeiro: Paz e Terra, 1987.

FREIRE, P. Educação na Cidade. 2. ed. São Paulo: Cortez, 1995.

LEITE, R. C. M.; FERRARI, N.; DELIZOICOV, D. (2001 jan/abr). A Historia das Leis de Mendel na Perspectiva Fleckiana. Revista Brasileira de Pesquisa em Educação em Ciências, Porto Alegre, v.1, n.2, p.97-108. Disponível em:< http://www.fae.ufmg.br/abrapec/revistas/V1-2/v1n2a9.pdf>. Acesso em: 10 jan., 2011.

LORENZETTI, L. (2008). Estilos de Pensamentos em Educação Ambiental: Um Estudo a partir das Dissertações e Teses. 2008. Tese (Doutorado em Educação Científica e Tecnológica) - Universidade Federal de Santa Catarina, Florianópolis, 2008.

MENEZEZ, L.C. (1988). Crise, cosmos, vida bumana: Física para uma educação humanista. 2008.Tese (Livre docência) - Universidade de São Paulo, São Paulo, 2008.

(1996). Paulo Freire e os Físicos. In: Moacir Gadotti. (Org.) Paulo Freire, uma bibliografia.

São Paulo: Ed. Cortez.

PERNAMBUCO, M. M. C. A. (1981). Ensino de Ciências a Partir de Problemas da Comunidade.1981. Dissertação (Mestrado) - Instituto de Física, Faculdade de Educação da Universidade de São Paulo, São Paulo, 1981.

Projeto ensino de ciências a partir de problemas da comunidade: uma experiência no Rio Grande do Norte. Brasília: CAPES/MEC/SPEC, 1983.

. Significações e realidade: conhecimento (a construção coletiva do programa). In: PONTUSCHKA, N. (Org.) Ousadia no diálogo: interdisciplinaridade na escola pública. São Paulo: Loyola, 1993.

. Educação e escola como movimento: do ensino de ciências à transformação da escola pública. 
1994. Tese (Doutorado) - Faculdade de Educação, Universidade de São Paulo, São Paulo, 1994. . et al. Projeto ensino de Ciências a partir de problemas da comunidade. In: Atas do seminário

Ciência Integrada e/ ou Integração entre as Ciênciass: teoria e prática. Rio de Janeiro: Editora UFRJ, 1988.

PIERSON, A. H. C. O cotidiano e a busca de sentido para o ensino de física. 1997. Tese (Doutorado em Educação) - Universidade de São Paulo, São Paulo, 1997.

PONTUSCHKA, N. (Org.). Ousadia no diálogo: interdisciplinaridade na escola pública. São Paulo: Loyola, 1994.

SAMPAIO, M. M. F.; QUADRADO, A. D.; PIMENTEL, Z. P. Interdisciplinaridade no município de São Paulo. Brasília: INEP, 1994.

SÃO PAULO. Secretaria Municipal de Educação. Cadernos de Formação 01, 02 e 03. Série Ação Pedagógica na escola pela via da interdisciplinaridade. São Paulo: DOT/SME-SP, 1990.

. Secretaria Municipal de Educação. Visões de área. Coleção de autores coletivos. São Paulo: SME/SP, 1992.

SLONGO, I. I. P. (2004). A producão acadêmica em ensino de biologia: um estudo a partir de teses e dissertações. Tese (Doutorado em Educação) - Universidade Federal de Santa Catarina, Florianópolis.

; DELIZOICOV, D. (2010). Teses e dissertações em ensino de Biologia: uma análise histórico-epistemológica. Investigações em Ensino de Ciências (Online), Porto Alegre, v. 15, p. 275296, 2010. Disponível em: <http://www.if.ufrgs.br/ienci/artigos/Artigo_ID237/v15_n2_a2010. pdf $>$. Acesso em: 02 dez. 2011.

TORRES, C. A.; O’ CADIZ, M. P.; WONG, P. L. Educação e democracia: a práxis de Paulo Freire em São Paulo. São Paulo: Cortez/Instituto Paulo Freire, 2002

ZANETIC, J. (1989). Física também é cultura. Tese. São Paulo: FEUSP. 
